\title{
LANGUAGE
}

$\infty$

\author{
Marta Orlik \\ Maria Curie-Skeodowska University (UMCS) in Lublin \\ MARTAORLIK@INTERIA.PL
}

\section{Formulaic Sequences in First Language Acquisition and Foreign Language Learning}

\begin{abstract}
Formulaic sequences constitute a large part of the language we speak. This group contains, for example, idiomatic expressions, proverbs, mnemonics, or larger texts taught as a whole, like songs or prayers. They seem to be stored in our mental lexicon rather than created from scratch every time they are needed. The aim of the present article is to examine some types of formulaic sequences and discuss their function in communication. First, the article describes how children acquire and make use of formulaic sequences when they start speaking English as their mother tongue. Secondly, the paper discusses the difference between learning English as an L1 and as an L2. The paper aims to discuss various strategies used by children who do not speak English but have to use it because they find themselves in English-speaking environments. Furthermore, the article discusses some selected issues concerning adults learning formulaic sequences and major problems connected with it. Such difficulties usually stem from not having enough linguistic input from native speakers and therefore not being able to recognise strings of words that are most likely to occur.
\end{abstract}

key words: formulaic sequences, formulas, fused strings, prefabricated chunks

\section{Introduction}

Soon after the beginning of learning English as a foreign language one is taught about the plural ending -s. This is how words such as 'cats', 'dogs', 'birds', etc., are created. It is usually done by applying the rule. On the other hand, native speakers of English seem not to follow the same strategy as EFL students do. Certainly, creating the word 'cat-s' from scratch every time it is needed is cognitively more demanding than using already existing in mental lexicon 'cats' as a separate lexical item, and this 
is when formulaic sequences come into play. However, a vital question arises: what is a 'formulaic sequence'? In their essay from the year 2000, Wray and Perkins give the definition as follows:

Our working definition of formulaic sequence will be: a sequence, continuous or discontinuous, of words or other meaning elements, which is, or appears to be, prefabricated: that is, stored and retrieved whole from memory at the time of use, rather than being subject to generation or analysis by the language grammar (Wray and Perkins 2000: 1).

Generally, sequences are strings of words that occur together in an identical form at least more than once (e.g., Wray 2002, 6-8; Wood 2010, 1-4; Wood 2015, 1-2). Then, they start to be recognised and perhaps memorised in this and not any other form. What is more, they seem to be stored in our mental lexicon (Wray 1999, cited in Hatami 2015, 2). Thus, when one needs a certain expression, one can retrieve it from their memory rather than create it from scratch every time, which would take more effort. Wood (2015) enumerates three main features of formulaic sequences:

The items will be:

1. Multi word

1. Have a single meaning or function

2. Be prefabricated or stored and retrieved mentally as if a single word (Wood 2015,3).

Now, some types of formulaic sequences will be enumerated to show the scope of the term.

Formerly, only idiomatic expressions like 'to kick the bucket' were considered formulaic, but then it has spread to other types of phrases: for example, proverbs (Wray and Perkins 2000,4). What is interesting, people can change idioms, as well as proverbs, to achieve a humorous, or ironic effect. However, then they cease to be formulaic, as they are created consciously and require certain modifications. Such changes are not characteristic of songs, rhymes, or prayers which are also considered to be formulaic, however, widely recognisable in one, fixed form.

Collocations, "the habitual and recurrent juxtaposition of semantically related words" (Firth 1957, cited in Bartsch and Evert 2014), are also referred to as formulaic sequences. These can be divided into restrictive collocations, which are expressions that are inextricably tied together: for instance, 'conduct/do research', and not 'make research'; frozen expressions like 'red herring' (Ackermann and Chen 2013, 2), or loose collocations in which some words are associated, but are not necessarily used together in a particular conversation: for example, the relation between words like 'time-worn', 'holes', and 'fix' (Redeker 1990, 367-368). There are also a lot of academic collocations, like 'as a result of', 'on the other hand' (Biber et al. 1999, 999). However, a collocation is not the only possible way of saying something, but the most common one. (Wray, 2002).

Another group of formulaic sequences contains lexical bundles. 
Pobrane z czasopisma New Horizons in English Studies http://newhorizons.umcs.pl Data: 26/04/2023 11:19:24

Formulaic Sequences in First Language Acquisition and Foreign Language Learning

Lexical bundles are recurrent expressions, regardless of their idiomaticity, and regardless of their structural status. That is, lexical bundles are simply sequences of word forms that commonly go together in natural discourse (Biber et al. 1999, 990).

Lexical bundles can be examined by studying a corpus, for example, in the research conducted by David Wood (2015). Expressions are listed according to their frequency. However, to be named a lexical bundle, an expression must appear in at least five or six texts by different authors, so as to reduce the risk of this particular structure being used only by a given person (Wood, 2015). Lexical bundles are, for example, 'I don't think so', 'Would you mind...'. 'In fact', 'I don't want to...', etc.

Mnemonics are also formulaic sequences. According to Longman Dictionary of Contemporary English Online a 'mnemonic' is 'something as a poem or a sentence that you use to help you remember a rule, a name etc.'. An example of it can be 'a shirt has one Collar and two Sleeves' for the word 'necessary', which can turn out to be problematic for some people.

While analysing various types of formulaic sequences mentioned above, one notices they play an important role in language. The following discusses their usage for various purposes. First of all, using formulaic sequences is necessary to make the processing effort more efficient, since drawing on already existing fused strings of vocabulary requires considerably less effort than creating them from the very beginning.. They also enable one to obtain some time to think about what they are going to say next when they create a speech ad hoc. Using for instance 'As I already mentioned' rather than speech fillers like 'umm' makes the speaker sound more sophisticated and gives the speech the impression of fluency. Furthermore, the risk of misunderstanding may be significantly reduced by using lexical items almost everyone is familiar with, namely linking expressions. By using them the speaker enables the recipient to trace their speech. For instance, on hearing 'on the other hand', the listener assumes that some kind of juxtaposition is going to be implemented (Wray 2002, 75).

Apart from using formulaic sequences to sound fluent and professional, people use them to obtain what they want. For instance, saying a sentence based on a formulaic sequence, 'can you open the window, please?', seems to be the most effective way of getting something done. Formulaic sequences can also attract other people's attention, for example, by using 'listen to me'. And, last but not least, formulaic sequences are used just because they sound right (Wray 2002, 74).

\section{Formulaic Sequences in First Language Acquisition}

Children who are surrounded by a given language from the day they are born obtain much more input of this language. Thus, they have an opportunity to hear formulaic sequences in context long before they even say a word. When they begin to speak, they tend to use their own fused strings of words based on what they hear from their care- 
takers. Such fused strings may include, for example, 'me no eating'. They try to imitate formulaic sequences used by adults and they treat them as unanalysable chunks. They try to sound fluent, and even when they do not know the exact words they need to express their needs, they usually use correct patterns of intonation, as well as word and sentence stress (Wray 2002, 195).

Researchers distinguish two basic types of language learning styles: referential and expressive (e.g., Wray 2002, 114-117; Goldfield 1987). Referential children tend to label everything and use language to name and talk about different objects rather than to communicate. These children are usually the first or the only ones in their families. They also usually have well-educated parents. Taking the factors into consideration, it can be assumed that referential children are shown a lot of labelled pictures and given various types of picture books, try to read, and finally name the pictures on their own. Referential children are more reserved when they speak, since they want to pronounce words correctly. They tend to observe and analye everything that surrounds them. As a result, they speak less than expressive children, but they are the ones that impress adults with how intelligible they speech. Furthermore, due to the fact that they analyse everything, they are better at understanding grammatical rules, and they do not rely on formulaic sequences as much as expressive children (Wray 2002, 114-117).

On the other hand, expressive children use language mainly for communication. They often have older siblings or are raised in an environment where there are a lot of people surrounding them. That gives them an opportunity to hear many different utterances used by members of their families in context, as well as observe the results of using those utterances. They do not analyse strings of words that are heard many times in an unchanged form, but they try to imitate them and to find out by trial and error what they can achieve by using that particular sequence. Thus, expressive children often babble and are not intelligible for almost anyone apart from their family members, who are used to their way of speaking. Those children do not analyse everything they hear; however, they do notice some grammatical patterns, which fosters their language control (Wray 2002, 114-117).

However, despite the fact that language acquisition usually begins with aural input, formulaic sequences occur also in written language (e.g., Wible 2008; Reynolds 2016). When a child learns how to read, the extensive part of their lexicon is acquired incidentally through reading. This strategy is even more effective due to the fact that while reading a book one concentrates more on the actual reading than on conscious learning (Reynolds 2016, 3).

\section{Formulaic Sequences in Foreign Language Learning}

Formulaic sequences in Foreign Language Learning are equally important as in First Language Acquisition. It is believed that the native-like use of collocations, idiomatic expressions is a crucial part of successful communication (e.g., Pawley and Syder 1983; Wray 2002, 94). 
To know a language is not just to recognise its individual words, but also to know how to use them together in a broader context. What makes learning a new language even more difficult, is the fact that even if some utterances are perfectly correct grammatically, they may not sound natural or native-like. The problem is, the EFL learners perceive formulaic sequences in a completely different way than native speakers. They usually do not see them as unanalysable lexical strings that are at some point decomposed to smaller units. Conversely, due to the fact that their input in class is mainly written, they have to recognise words as parts of bigger lexical structures (Wible $2008,5)$. Moreover, detecting formulaic sequences as unknown is far more difficult than in the case of individual words, since sometimes they are composed of words known to the learner and do not instantly trigger the need to check them in a dictionary (Wible 2008, 11).

\subsection{Children}

To start learning a new language, children need to understand the fact that more than one language is spoken in the world. Only then can they find out who speaks which language and how they can communicate with other people. Usually, they are made aware of that fact at school, or through their parents who, for instance, show them films in different languages. ${ }^{1}$ Wray (2002) describes an ideal situation for children to learn another language: when they acquire it along with, or soon after they have acquired, their mother tongue. This takes place when one of their parents speaks their target language, or when they are sent to a bilingual kindergarten. Wray $(2002,150-157)$ and Wood $(2015,162-163)$ examine certain aspects of learning a language by children. For instance, they have to express themselves somehow to get their basic needs satisfied. It gives the best results when children do not have anyone to talk to in their first language. For example, if they do not know how to ask for some food, and their teacher is not perceptive enough to see that they are hungry, they may starve for even a few hours until their parents take them home.

But apart from being fed, cuddled, or simply looked at, or given attention, children also have to establish social links with their peers. When they are not able to produce their own sentences yet, they usually repeat what they hear. Then, when they become proficient at repeating, they are no longer satisfied with that, and therefore, they start to produce sentences on their own. They often use formulaic sequences to learn new vocabulary (they tend to say 'what's this?', or 'how do you say X?' all over again). This is the best time for learning formulaic sequences, because they are not analysed and have not been segmented into individual lexical units yet (Wray 2002, 156; Wood $2015,162)$. When children cannot reproduce the exact utterances of people who surround them, they tend to use English (or any other language), saying gibberish with the

1 This is not the case with bilingual or multilingual children who are exposed to two or more languages from their birth. 
same stress and intonation just to be as close to the original as they can (Wray 2002, 154). This evidenced when children are asked to repeat a phrase in class; they hear it as a whole, and are unable to decompose it into individual words, even when they are reading from their books.

Children are usually taught by direct instruction. Since many of them cannot read yet, they have to be taught lexical items explicitly, be it individual words or longer expressions. However, at some point, children want to express novel ideas and try to formulate their utterances on their own, with the results of sounding less native-like and fluent. Without an ability to think in a foreign language they, as many of adult learners, try to translate whole sentences from their mother tongue, sometimes completely ignoring the grammar of their target language, not to mention its formulaicity (Pawley and Syder 1983). When students are old enough to understand some abstract concepts of grammar, they are able to form their own sentences. This is the time when they treat individual words like building blocks that enable them to construct some bigger phrases. However, formulaic sequences do not cease to exist, because they are always available, stored in the mental lexicon (Wray 2002, 171).

\subsection{Teenagers and adults}

However, learning English as a foreign language is somewhat different in the case of teenagers and adults than with children. First, they seem to have a different motivation for learning. Usually they start to see it as a way of improving their qualifications in the workforce or enhancing their chances to communicate with native speakers during their travels, etc., rather than as an abstract subject taught at school. Moreover, those who started learning English earlier on, and therefore have a fairly good command of it, are able to read books in their target language, which significantly expands their lexicon (Reynolds 2016).

What is quite similar, however, is the necessity to learn formulaic expressions. Unfortunately, teachers at school often tend to concentrate more on individual words than on longer expressions, since they are more convenient and easier to teach and learn (e.g., Alali and Schmitt 2012; Hatami 2015). As a result, this can lead to the point where students are able to form perfectly correct sentences, yet not sound fluent and native-like due to their lack of knowledge of formulaic sequences (Alali and Schmitt 2012,3). Thus, they are an important part of language that should be learnt. Acquiring them incidentally while reading (Reynolds 2016,3), or listening seems to be the best way to master them. However, this technique is rather time-consuming and it does not guarantee an immediate success (Alali and Schmitt 2012, 3). Therefore, formulaic sequences should be taught explicitly in class.

However, due to the limited time, teachers have to be selective in choosing appropriate items. Omidian, Shahriari and Ghonsooly (2016) enumerated lists of useful expressions created by different scholars, for instance, by Biber et al. (2012); Simpson-Vlach and Ellis (2010), which they called the Academic Formulas List; and by 
Formulaic Sequences in First Language Acquisition and Foreign Language Learning 23

Martinez and Schmitt (2012), which they called PHRASE List. Interestingly, the key factor in choosing particular sequences was not always their frequency, but rather their usefulness and clearly defined meaning.

Once the expressions are chosen, there are various techniques that enable teaching them. Unfortunately, students usually learn by heart new formulaic sequences given to them by their teachers (Cook 1994). Rote learning may, indeed, prove useful in learning to recognise particular word strings, but may not be enough to recall them (Alali and Schmitt 2012, 14-15). To effectively teach formulaic sequences, the teacher has to first of all make their students aware of the importance of them in fluent speech (Hatami 2015, 8). Then, they should use some cognitively engaging exercises. These can be, for example, written exercises like filling in the blanks, etc., since they usually provide broader context unlike lexical drills (Alali and Schmitt 2012, 20). Students can also be involved in role-play activities (Hatami 2015, 12).

Another way of teaching formulaic sequences is showing the students correspondences between conceptual metaphors and their linguistic representations. An example of this may be blow up=inhale, as an instance of the schema more is up (Boers 2000, cited in Alali and Schmitt 2012). Other instances of that may be conceptual metaphors include +TIME IS MONEY+ and expressions like to spend time, to gain some time, etc. This also helps to put formulaic sequences in a broader context, since it appeals to the common sense of students.

\section{Concluding remarks}

To sum up, formulaic sequences are the essential part of language that helps learners to communicate and boost their linguistic confidence. The most effective way to acquire formulaic sequences is by reading and listening extensively to different materials in the student's target language. However, this is a fairly time-absorbing process and it does not give immediate results for everyone. Therefore, formulaic sequences should be taught in class. Putting formulaic sequences in context seems to be a vital way for students to acknowledge their importantance in everyday communication (e.g., Reynolds 2016). After examining selected aspects of acquisition and learning of formulaic sequences, the author of the present article would like to focus more on various techniques used to teach them in a classroom environment.

\section{References}

Ackermann, Kirsten, and Yu-Hua Chen. 2013. "Developing the Academic Collocation List (ACL) - A corpus-driven and expert-judged approach." Journal of English for Academic Purposes 12(4):235-247. 
Alali, Fatima A., and Norbert Schmitt. 2012. "Teaching Formulaic Sequences: The Same as or Different From Teaching Single Words?” TESOL Journal 3:153-180.

Bartsch, Sabine, and Stefan Evert. 2014. "Towards a Firthian notion of collocation" In Vernetzungsstrategien, Zugriffsstrukturen und automatisch ermittelte Angaben in Internetwörterbüchern, ed. Andrea Abel and Lothar Lemnitzer, number 2/2014 in OPAL - Online publizierte Arbeiten zur Linguistik, 48-61. Mannheim: Institut für Deutsche Sprache.

Biber, Douglas, Stig Johansson, Geoffrey Leech, Susan Conrad, and Edward Finegan. 1999. Longman Grammar of Spoken and Written English. Harlow: Pearson Education Limited.

Cook, Guy. 1994. "Repetition and learning by heart: An aspect of intimate discourse, and its implications" ELT Journal 48 (2):133-141.

Goldfield, Beverly. 1987. "The contributions of child and caregiver to referential and expressive language." Applied Psycholinguistics 8(3):267-280.

Hatami, Sarvenaz. 2015. "Teaching Formulaic Sequences in the ESL Classroom.” TESOL Journal 6:112-129.

Myles, Florence, Janet Hooper, and Rosamond Mitchell. 1998. "Rote or rule? Exploring the role of formulaic language in classroom foreign language learning." Language Learning 48(3):323-363.

Omidian, Taha, Hesamoddin Shahriari, and Behzad Ghonsooly. 2016. "Evaluating the Pedagogic Value of Multi-Word Expressions Based on EFL Teachers' and Advanced Learners' Value Judgements" TESOL Journal. doi:10.1002/tesj.284

Pawley, Andrew, and Frances H. Syder. 1983. "Two puzzles for linguistic theory: nativelike selection and nativelike fluency" In Language and communication, ed. Jack C. Richards and Richard W. Schmidt, 191-226. New York: Longman

Redeker, Gisele. 1990. "Ideational and pragmatic markers of discourse structure." Journal of Pragmatics 14(3):367-381.

Reynolds, Barry L. 2016. "The Effects of Target Word Properties on the Incidental Acquisition of Vocabulary Through Reading." The Electronic Journal for English as a Second Language 20(3). Accessed May 26 on http://www.tesl-ej.org/pdf/ej79/a4.pdf

Wible, David. 2008. "Multiword expressions and the digital turn" in Phraseology in Foreign Language Learning and Teaching, ed. Fanny Meunier and Sylviane Granger, 163-180. Amsterdam: John Benjamins Publishing Company

Wood, David. 2010. Perspectives on Formulaic Language: Acquisition and Communication. London: Bloomsbury Publishing

Wood, David. 2015. Fundamentals of Formulaic Language: An Introduction. London: Bloomsbury Publishing.

Wray, Alison, and Michael Perkins. 2000. "The functions of formulaic language: an integrated model". Language in Communication 20:1-28.

Wray, Alison. 2002. Formulaic Language and the Lexicon. Cambridge: Cambridge University Press. 